\title{
Cinnamomum cassia bark produced by solid-state fermentation with Phellinus baumii has the potential to alleviate atopic dermatitis-related symptoms
}

\author{
YONG-KYU SHIN ${ }^{1,2}$, HYEONG-U SON ${ }^{3}$, JONG-MYUNG KIM ${ }^{2}$, \\ JIN-CHUL HEO ${ }^{4}$, SANG-HAN LEE ${ }^{3,4}$ and JONG-GUK KIM ${ }^{1}$ \\ ${ }^{1}$ Department of Microbiology, Kyungpook National University; ${ }^{2}$ Farmbios Co. Ltd., Techno Building; \\ ${ }^{3}$ Department of Food Science and Biotechnology; ${ }^{4}$ Food and Bio-Industry Research Institute, \\ Kyungpook National University, Daegu 702-701, Republic of Korea
}

Received July 25, 2014; Accepted November 14, 2014

DOI: $10.3892 / \mathrm{ijmm} .2014 .2006$

\begin{abstract}
In order to evaluate whether the aqueous fraction of Cinnamomum cassia produced by solid-state fermentation with Phellinus baumii $(\mathrm{afCc} / \mathrm{Pb})$ inhibits atopic symptoms in vivo, its efficacy was evaluated in an animal model of 2,4-dinitrofluorobenzene (DNFB)-induced atopic dermatitis. Immune-related cells were quantified using hematoxylin and eosin staining, and phenotypic cytokines, enzymes and the expression of other proteins in the animal model were evaluated. The data revealed that af $C c / P b(100 \mu \mathrm{g} / \mathrm{ml})$ exhibited strong anti-atopic activity, causing a significant $40 \%$ reduction in immune response, as shown by the extent of ear swelling, resulting from a decrease in the number of eosinophils in the skin tissues due to decreased matrix metalloproteinase- 2 and interleukin-31 expression. These results collectively suggest that af $C c / P b$ has the potential to alleviate the symptoms of atopic dermatitis in a mouse model of DNFB-induced atopic dermatitis, and that it may be a valuable bioresource for the cosmetic/cosmeceutical industry.
\end{abstract}

\section{Introduction}

Cinnamomum cassia (C. cassia) has been used traditionally to treat immune diseases, as well as dyspepsia, gastritis and anti-glycemic disturbances (1). The plant has acrid, aromatic, astringent, carminative, deodorant, diuretic, stimulant and sweet characteristics in nature. However, the anti-allergic properties

Correspondence to: Dr Sang-Han Lee or Dr Jong-Guk Kim, Department of Food Science and Biotechnology, Kyungpook National University, 80 Daehakro, Daegu 702-701, Republic of Korea E-mail: sang@knu.ac.kr

Dr Jong-Guk Kim, Department of Microbiology, Kyungpook National University, 80 Daehakro, Daegu 702-701, Republic of Korea E-mail: jgkim@knu.ac.kr

Key words: Cinnamomum cassia, aqueous fraction, atopic dermatitis, solid fermentation, Phellinus baumii of $C$. cassia have not been fully elucidated using in vivo animal models. The dried bark of $C$. cassia is used not only as a preventive/therapeutic agent for various diseases, but as a flavoring or seasoning in various foods (2). The bark of the tree is known as cinnamon, which is rich in essential oils and tannins, and inhibits the growth of several types of microbes (3).

Allergy is a symptom that develops in response to invasion of antigens in the human body (4). During allergic inflammation, mast cells produce immunoglobulin E (IgE), which attaches to the mast cells within the tissues and is combined with IgE of the mast cells. The mast cells, in turn, produce a number of substances, such as histamine, serotonin and lenin, which cause sneezing or itching (5). 2,4-Dinitrofluorobenzene (DNFB) can be used to induce the symptoms of delayed-type contact allergic dermatitis in mice (6). Repeated exposure to this substance can cause skin swelling and thickening of skin tissues due to the infiltration of type 1 helper T-cell-mediated inflammatory cells (7). Therefore, it is suitable for use in an animal model for the research of atopic dermatitis.

In the course of screening for anti-atopic agents from various traditional Korean herbal plants, using an in vivo DNFB-induced animal model, it was found that the $C$. cassia extracts, produced by solid-state fermentation, have the potential to inhibit atopic symptoms. Therefore, to investigate the synergistic and protective effects of the aqueous fraction produced by solid fermentation of Phellinus baumii on the surface of $C$. cassia (afCc/Pb) in an atopic dermatitis model, the anti-atopic activity of the extracts was first tested using a DNFB-induced animal model.

The typical method of fermentation is performed using liquid culture. Such a liquid fermentation has low efficiency in biotransformation as it uses substances only available for extraction (8). In particular, when herbal plants or Oriental medicines are used as fermentation substrates, the substrate is not effectively fermented and the choice of substances for fermentation is limited, as there is not efficient utilization of the cellulose, hemicelluloses and lignin (9). Therefore, the search for new bioactive substances through simple extraction or the liquid fermentation of natural substances is limited by these factors (10). The use of fungi for solid-state fermentation is 
advantageous, as it allows biotransformation that leads to the production of food or biomaterials with greater health benefits, although the precise mechanisms of substrate extraction from fungi and what types of useful biomaterials could be produced remain unknown. For this reason, using the aqueous fraction of Cinnamomum cassia produced by solid-state fermentation with $P$. baumii (afCc/Pb), the present study attempted to extract efficient biomaterials through solid-state fermentation; this process was different from liquid-state bacterial or yeast fermentation that have been widely used in food and bio-industry.

In the study, it was found that af $C c / P b$ has potent efficacy in inhibiting atopic-dermatitis and, thereafter, assessed the ameliorating effects of afC $c / P b$ on DNFB-induced atopic dermatitis in mice. Various biochemical analyses were conducted to assess antioxidant parameters, cytokine levels and phenotypic atopic symptoms in order to ascertain whether afC $\mathrm{C} / \mathrm{Pb}$ has potential in alleviating the symptoms of atopic dermatitis.

\section{Materials and methods}

Materials and reagents. DNFB (Sigma, St. Louis, MO, USA; dissolved in acetone) was sterile filtered and used for induction of atopic dermatitis in mice. Formalin (Sigma), hydrogen peroxide (Sigma) and all other materials were commercially available.

Animals.C57BL/6mice(6-7 weeks of age, male) were purchased from Samtaco Korea (Osan, Korea). The mice were housed in an air-conditioned animal room, at a temperature of $22 \pm 1^{\circ} \mathrm{C}$ and a humidity of $65 \pm 5 \%$. All the procedures were performed in compliance with the Research and Ethical Guidelines of the Committee of the International Association for the Study of Pain (11) and with the in-house guidelines of the University (Kyungpook National University, Daegu, Korea). The rules and in-house guidelines for animal experiments, including ethical care, were strictly adhered to under the guidance of the University Committee. Animals were allowed to adapt to the laboratory atmosphere for $<1$ week before the experiments. The number of each experimental group was limited to five.

Solid fermentation of P. baumii Pilat on C. cassia. The plant extracts were collected from samples as described by Cho et al (12), with a slight modification. P. baumii (stocked at Farmbios Co., Ltd., Daegu, Korea) was prepared using solid-state fermentation (12). The stock cultures were inoculated on a potato dextrose agar (PDA) slant incubated at $25^{\circ} \mathrm{C}$ for 7 days, maintained by monthly subculture and the slants were stored at $4^{\circ} \mathrm{C}$. P. baumii was grown initially on PDA medium $(2.4 \%$ potato dextrose broth and $2 \%$ agar) in a petri dish and subsequently transferred to a seed culture medium by cutting each portion $(1 \times 1 \mathrm{~cm}, 3$ pieces) of the agar plate with a sterilized cutter. The seed culture for P. baumii was grown in a $500-\mathrm{ml}$ flask containing $100 \mathrm{ml}$ of potato dextrose broth at $25^{\circ} \mathrm{C}$ with a shaker (SI-600R, Jeio-Tech, Seoul, Korea) at $130 \mathrm{rpm}$ for 7 days. The $C$. cassia sample (100 g) was autoclaved $\left(121^{\circ} \mathrm{C}, 30 \mathrm{~min}\right)$ in a $1000-\mathrm{ml}$ flask, and subsequently, $20 \mathrm{ml}$ of seed culture was added and cultivated under the following conditions: Temperature, $25^{\circ} \mathrm{C}$; moisture, $80 \%$; and period, 20 days. The fermented plant was sliced and mixed in
10 volumes of hot water, stirred vigorously for $2 \mathrm{~h}$ and centrifuged at 9,300 x $\mathrm{g}$ for $20 \mathrm{~min}$, and thereafter, the supernatants were collected and stored at $4^{\circ} \mathrm{C}$. The $C$. cassia was obtained at DaeHun Medicinal Co. in Daegu, Korea between October and November 2009, as identified by a senior staff member of Kyungpook National University. The voucher specimens of the plant have been deposited in the Lab of Enzyme Biotechnology, Kyungpook National University.

A DNFB-induced atopic animal model. A DNFB-induced atopic animal model was used, as described previously $(8,13)$. In brief, the primary sensitization involved the application of $50 \mu 10.5 \%$ (w/v) DNFB solution to a fragment of clipped abdominal skin. A cutaneous reaction was evoked in the skin of the ear by repeated applications of $20 \mu \mathrm{l} 0.2 \%$ (w/v) DNFB solution. The DNFB challenge was repeated 4 times every 3 days for 2 weeks, beginning 5 days after the initial sensitization (days 5, 8, 11 and 14). Vehicle mice were similarly treated with acetone, and without DNFB. Extracts of $C$. cassia and $P$. baumii or afCc/Pb were topically administered on 8 occasions (days 6, 7, 9, 10,12,13,15 and 16), once a day for 2 weeks, beginning the day after the first DNFB re-sensitization (day 6) for DNFB challenge.

Hematoxylin and eosin $(H \& E)$ staining and cytotoxicity assay. H\&E staining was carried out as described previously (14). Cell viability was assayed using a cell counting kit-2 (Dojindo, Gaithersburg, MD, USA), as described elsewhere (15).

Measurement of ear swelling and eosinophil count. Ear thickness was measured using a vernier caliper (AMI, Painesville, $\mathrm{OH}$, USA). Compared to other immune cells, eosinophils have a unique morphology in shape when atopic dermatitis symptoms occur. Therefore, eosinophil numbers were counted using a morphological feature at a designated area in the H\&E stained cells by comparing the control and af $C c / P b$-treated samples, as described previously in detail with a slight modification (16).

$\beta$-hexosaminidase assay. The degranulation of RBL-2H3 cells was evaluated by measuring the activity of the granule-stored enzyme, $\beta$-hexosaminidase, secreted in the extracellular medium. RBL-2H3 cells $\left(2 \times 10^{5}\right.$ cells/well $)$ were seeded with minimum essential medium (MEM; 41500-034, Gibco, Carlsbad, CA, USA) in a 24-well plate (Corning, New York, NY, USA) and sensitized with $1 \mu \mathrm{g} / \mathrm{ml}$ of DNP-IgE (D8406, Sigma) at $37^{\circ} \mathrm{C}$ in $5 \% \mathrm{CO}_{2}$ overnight. Siraganian buffer [119 mM NaCl, $5 \mathrm{mM} \mathrm{KCl,} 0.4 \mathrm{mM} \mathrm{MgCl} 2,25 \mathrm{mM}$ piperazine- $N, N$ '-bis[2-ethanesulfonic acid], $5.6 \mathrm{mM}$ D-glucose, $1 \mathrm{mM} \mathrm{CaCl}_{2}, 0.1 \%$ bovine serum albumin (BSA)], was adjusted to $\mathrm{pH} 7.2$ with $\mathrm{NaOH}$, and was prepared shortly before use. After washing wells twice with $500 \mu \mathrm{l}$ siraganian buffer, the cells were incubated in $180 \mu \mathrm{l}$ sample with buffer for $30 \mathrm{~min}$. In order to stimulate the cells, $20 \mu \mathrm{g}$ dinitrophenyl (DNP)-BSA (D5050; Biosearch Technologies, Inc., Novato, CA, USA) was added and incubated at $37^{\circ} \mathrm{C}, 5 \% \mathrm{CO}_{2}$ for $1 \mathrm{~h}$. Following incubation, $50 \mu \mathrm{l}$ supernatant was transferred to a 96 -well plate and the substrate for $\beta$-hexosaminidase $[1 \mathrm{mM}$ 4-nitrophenyl $N$-acetyl- $\beta$-D-glucosaminide (N9376, Sigma)], in $0.1 \mathrm{M}$ citrate buffer ( $\mathrm{pH} 4.5$ ), was added. After incubation at $37^{\circ} \mathrm{C}$ for $1 \mathrm{~h}$, 
$200 \mu 1$ stop solution $\left(0.1 \mathrm{M} \mathrm{Na}_{2} \mathrm{CO}_{3} / \mathrm{NaHCO}_{3}\right)$ was added and the sample was measured at $405 \mathrm{~nm}$ with a spectrophotometer (VICTOR3; Perkin Elmer, Wellesley, MA, USA). $\beta$-hexosaminidase release was calculated as the activity in the DNP-BSA treatment group compared to that in the control (17).

$$
\begin{gathered}
\% \text { degranulation }=\left(O D_{\text {sample treatment }}-O_{\text {no stimulation }}\right) / \\
\left(\mathrm{OD}_{\text {stimulation }}-\mathrm{OD}_{\text {no stimulation }}\right) \times 100
\end{gathered}
$$

Mouse spleen cell culture and measurement of interleukin-4 $(I L-4)$. Mouse spleen cells were primary-cultured from C57BL/6 mice (male, 10 weeks) as previously described (18). Dissected mouse spleen was homogenized and blended with RPMI medium including penicillin and streptomycin. Cell-suspended medium was filtered using a cell strainer (BD Falcon, Franklin Lakes, NJ, USA). Separated crude splenocytes were treated with red blood cell lysis buffer (Sigma) and washed with phosphate-buffered saline (PBS). Processed cells were incubated with $10 \%$ fetal bovine serum in RPMI medium on a 96 -well plate, at $37^{\circ} \mathrm{C}$ for $24 \mathrm{~h}$. Concanavalin A $(3 \mu \mathrm{g} / \mathrm{ml})$ and the samples were added and incubated again for $24 \mathrm{~h}$. The cell supernatants were used for cytokine measurement by an IL-4 enzyme-linked immunosorbent assay kit (SM4000B, R\&D Systems, Minneapolis, MN, USA).

Reverse transcription polymerase chain reaction (RT-PCR) analysis for $m R N A$ expression. RAW264.7 cells were treated with sample extract $(10$ and $30 \mu \mathrm{g} / \mathrm{ml})$ for $5 \mathrm{~h}$ and lipopolysaccharide $(1 \mu \mathrm{g} / \mathrm{ml})$ for $4 \mathrm{~h}$. Following release of the cell supernatant, RNA was isolated using TRIzol ${ }^{\circledR}$ reagent. Total RNA was calculated as the measurement at $260 \mathrm{~nm}$ and $200 \mathrm{ng}$ total RNA was reverse transcribed using Maxime RT-PCR PreMix (iNtRON Biotechnology, Seongnam, Korea) at $45^{\circ} \mathrm{C}$ for $30 \mathrm{~min}$. The cDNA was amplified using the following primers: Matrix metalloproteinase-3 (MMP-3), F: ACACCGGATTTGCCAAGACA, R: GTGGGTACCACGAGGACATC, 467 basepair (bp); MMP-10, F: GGTGGCTTCAGTACCTTCCC, R: CTGAG GGTGCAAGTGTCCAT, 334 bp; $M M P-12$, F: TCCATAT GGCCAAGCATCCC, R: TTTGGTGACACGACGGAACA, $411 \mathrm{bp} ;$ MMP-14, F: ACAAGGACTTTGCCTCTGAAGG, R: GTGCAGAGCCTTGACAACATTC, 254 bp; and mouse glyceraldehyde-3-phosphate dehydrogenase $(G A P D H)$ as an internal control, F: GCGAGACCCCACTAACATCA, R: GAG TTGGGATAGGGCCTCTCTT, $335 \mathrm{bp}$, which were synthesized by Bioneer (Daejeon, Korea). Following the amplification process, $10 \mu 1$ of each product was determined using $1.5 \%$ agarose gel electrophoresis and visualized using Red safe (iNtRON Biotechnology). In order to determine the position of each amplified lane, a 1-kb DNA ladder (Solgent, Daejeon, South Korea) was used. The relative amounts of amplified cDNA were normalized with 18 s RNA and calculated using the Molecular Imager Gel Doc XR System and Quantity One 1-D analysis software (Bio-Rad, Hercules, CA, USA) (19).

Immunohistochemistry. Ear tissues were cut lengthways and fixed with $10 \%$ formalin solution in PBS for $24 \mathrm{~h}$. Paraffin sections were fixed lengthways and transferred to slides. In order to inhibit endogenous peroxidase activity, samples were treated with methanol containing $3 \%$ hydrogen peroxide solution. Sections were treated with a $10 \%$ normal goat serum for $1 \mathrm{~h}$. The slides were incubated overnight at $4^{\circ} \mathrm{C}$ with rabbit anti-mouse MMP-2 (sc-8835; Santa Cruz Biotechnology, Santa Cruz, CA, USA) or IL-31 (ab102750; Abcam Inc., Cambridge, MA, USA) (20).

Gelatin zymography assay. In order to determine MMP-9 activity, gelatin zymography was assayed as previously described (21). Briefly, RAW264.7 cells were seeded on 6-well plates and incubated for $24 \mathrm{~h}$. The culture medium was changed to serum-free Dulbecco's modified Eagle's medium with sample treatment and incubated for $12 \mathrm{~h}$. Cell culture medium was collected and the amount of protein calculated using bicinchoninic acid protein assay reagent (Sigma). Electrophoresis was conducted using sodium dodecyl sulfate acrylamide gel with $1 \%$ gelatin. Following electrophoresis, the gels were washed twice with 2.5\% Triton X-100 (Sigma), and incubated in developing buffer $(1.21 \mathrm{~g}$ Tris base, $6.3 \mathrm{~g}$ Tris $\mathrm{HCl}, 11.7 \mathrm{~g} \mathrm{NaCl}, 2.74 \mathrm{~g} \mathrm{CaCl}$, and $0.02 \%$ Brij, adjusted to 11 with distilled water) at $37^{\circ} \mathrm{C}$ with agitation for $16 \mathrm{~h}$. The gels were stained with Coomassie blue and destained in buffer (10\% acetic acid and 40\% methanol in distilled water). MMP-9 activity was measured as the resolved gel band using Chemi Doc $^{\mathrm{TM}} \mathrm{XRS}^{+}$with Image Lab software (Bio-Rad).

Statistical analysis. Data are expressed as mean \pm standard deviation. Statistical significance was determined using one-way analysis of variance with Tukey post-hoc analysis using the SPSS 19.0 program (SPSS, Chicago, IL, USA) (22). The critical level for significance was set at $\mathrm{P}<0.05$ or $\mathrm{P}<0.001$, which were considered to indicate a statistically significant difference.

\section{Results and Discussion}

In the course of screening for anti-atopic agents from natural resources, such as food and/or Oriental herb plants, an aqueous fraction produced by solid-state fermentation on the surface of C. cassia bark was found to have potential in ameliorating atopic dermatitis, as confirmed by in vitro, as well as in vivo assays.

The Phellinus sp. is an invaluable medicinal mushroom that is called SangHwang in Korea (23). It is commonly grown in a humid environment on the surface of several types of hardwood trees, such as oak, chestnut and mulberry (23). Several examples of the Phellinus sp. are well known in Korea, including $P$. linteus, P. baumii, P. rimosus and P.mori. Recently, the Korea Food \& Drug Administration issued a guideline on the use of these mushrooms due to their specific hepatotoxic and nephrotoxic effects, even the efforts for regulating the use of products based on their physicochemical properties (24). However, the mushrooms are extremely important for medicinal and nutraceutical purposes. The main effective constituents originate from polysaccharides and/or their complexes. There are numerous studies on the anti-tumor, anti-diabetic and anti-inflammatory activities of the known and/or unknown extracts/fractions from these mushrooms $(25,26)$. Primarily, mushrooms, including Basidiomycetes, can degrade environmental biomaterials, such as cellulose, hemicelluloses and lignin as substrates.

To expand the biological applications, whether the mushroom P. baumii decreased the toxicity of $C$.cassia bark was first 
tested using solid-state fermentation. Solid-state fermentation is a biomolecule-manufacturing or toxicant-degrading process used in the food, pharmaceutical and cosmetic industries, although submerged fermentation has advantages for mass production, space, cost and manpower (27). For the purpose of medicinal use of Oriental herbs, it is known that cytotoxicity is a barrier. Therefore, the present study tried to evade cytotoxicity, such as estrogen-like activity, by performing solid-state fermentation of the Phellinus species.

Firstly, the optimal culture conditions for P. baumii (Fig. 1a and c) were evaluated, which exhibited the most potent activity. The optimal temperature for mycelial growth of $P$. baumii was between $25^{\circ} \mathrm{C}$ and $30^{\circ} \mathrm{C}$ (data not shown), and the growth reached a maximum when PDA medium, out of the 6 media tested [PDA, yeast malt, minimal culture medium (MCM), Czapek's, oak extract and pine extract], was used, after 14 days cultivation. The density and color of the mycelia were compact and yellowish, respectively. Maximal growth was $37.7 \pm 0.6 \mathrm{~mm}$ on PDA medium, whereas it was $33.5 \pm 4.0 \mathrm{~mm}$ on MCM medium (data not shown). The optimal $\mathrm{pH}$ for growth was between 5.0 7.0, whereas at a $\mathrm{pH}<4.0$ growth was markedly decreased.

In total, 200 types of medicinal herbs were prepared that were fermented by P. baumii (Fig. 1a). During solid-state fermentation, culture was carried out for 60 days at $25-30^{\circ} \mathrm{C}$ and $60 \%$ humidity, which are optimal conditions for growth. As a result, 200 types of fermentation broths were achieved using the fermentation procedure, while 76 fermentation broths were discarded as the broths were contaminated with other bacteria or fungi. The fractions were prepared through extraction with 6 solvents (water, ethanol, methanol, ethyl acetate, chloroform and hexane). To determine the maximal conditions for anti-atopic dermatitis activity, 456 types of extracts were tested using an antioxidant in vitro assay (data not shown) and a DNFB-induced animal model.

The total antioxidant activities of $C$. cassia bark extract, $P$. baumii extract or afCc/Pb were first examined. When theses samples were applied to in vitro antioxidant assays, the antioxidant activity was increased by the aqueous fraction produced by solid fermentation, whereas cytotoxicity was not. An in vivo anti-atopic experiment was subsequently carried out. Mouse ear inflammation was induced using DNFB (Fig. 2a, 2nd image), an inducer of chemically contact dermatitis. To determine the extent of inflammation and damage to the ear, samples were treated with (Fig. 2a, 5th image) or without (Fig. 2a, 3rd and 4th images) af $C \mathrm{C} / \mathrm{Pb}$. Compared to the control, the DNFB-treated group showed significantly increased ( $<4.2$-fold) inflammation response on the ear, as determined by measuring ear thickness (Fig. 2b, 1st and 2nd images). The swollen ear morphology was rough, not clean or smooth, with no brightness, and with numerous ruffles (Fig. 2a, 2nd image). Based on a number of samples, af $C c / P b$ was therefore selected for further study. In control mice, no lesions or inflammation of the skin were found (Fig. 2a, 1st image), whereas the DNFB-treated ears were severely damaged (Fig. 2a, 2nd image), however, treatment with $\mathrm{Cc} / \mathrm{Pb}$ alleviated the symptoms of such damage (Fig. 2a, 5th image). Histological observations revealed that DNFB-treated ears had a 4.2-fold thicker swelling than those of the control group, showing that there were numerous immune cells ( $>7$ times than that of the control) in the area of the dermis or epidermis (Fig. 2a-c; comparing the 2 nd and 5th images). These increased levels were evidently decreased in a concentration-dependent manner by treatment with afCc/Pb (data not shown). The ear tissues were cut, sectioned and histological staining was applied to assess whether the DNFB-induced damage was alleviated in the afCc/Pb-treated mice. The results showed that afC $C / P b$ has potential in mitigating DNFB-induced atopic symptoms; re-sensitization caused bad scarring and eczema on the skin, however, in comparison to the control (Fig. 2, comparing 1st and 5th images), af $C \mathrm{c} / \mathrm{Pb}$ treatment reduced and mitigated the characteristic symptoms of atopic dermatitis (Figs. 2 and 3). To further confirm the preventive effects of af $C c / P b$, the thickness of ear swelling was measured. As shown in Fig. 3, the ear thickness of control mice was $167.7 \mu \mathrm{m}$, whereas that of the DNFB-treated mice indicated a 4.2-fold increase in swelling (6). However, compared to the ear thickness of DNFB-treated mice, that of the afCc/Pb-treated mice was markedly decreased, showing a $<21 \%$ reduction in the thickness of the ear epidermis. Following the same pattern, the ear dermis was also thinner than that of the induced group (data not shown). These results strongly indicate that af $\mathrm{Cc} / \mathrm{Pb}$ treatment decreased ear swelling, as well as ear thickness by ameliorating the dermal/epidermal microenvironment. DNFB exacerbated the inflammation in the skin, broadened the thickness of scarring and eczema, and the stained inflammatory cells evidently increased in number. By contrast, the expression of immune-related cells was reduced by afCc/Pb treatment (Figs. 2c, 3c and d). Total cell counts showed that inflammation-related cells increased in number by 7.1 -fold in response to DNFB treatment, while they decreased to $38 \%$ of the control following af $C c / P b$ treatment. The number of eosinophils in the afCc/Pb group was significantly lower than that of the $\mathrm{Cc}$ - or $\mathrm{Pb}$-treated groups. This decrease in eosinophil numbers may be associated with the active ingredients of af $C c / P b$ that have anti-atopic activity (Figs. 2, 3b and d). The balance between various cytokines plays a key role in the remodeling of the skin dermal and epidermal environment. Numerous enzymes are also associated with the regulation between the skin epithelial boundaries.

Furthermore, as shown in Fig. 4a and b, MMP-2 expressed cells on mouse ear tissue were significantly increased in the DNFB-treated group, while they were decreased in af $C c / P b$-treated mice.Zymography in RAW264.7 cells revealed that compared to those of the DNFB-induced group, the MMP-9 expression levels following afCc/Pb treatment $(30 \mu \mathrm{g} / \mathrm{ml})$ were markedly reduced in a concentration-dependent manner (Fig. 4d), suggesting that af $C c / P b$ inhibits DNFB-induced skin erosion. Subsequently, the expression levels of other mRNA were measured by RT-PCR. Notably, elevated MMP-10 levels decreased following treatment with $30 \mu \mathrm{g} / \mathrm{ml}$ afCc/Pb (Fig. $4 \mathrm{c}$, lane 4,2 nd column). The erosion or eczema of the skin appears to involve the expression of matrix-associated proteases. It is possible that MMP-10 was upregulated in the atopic dermatitis tissue sample $(28,29)$. In particular, it is known that MMP-8 and MMP-9 have potential in coordinating skin remodeling or regeneration during inflammatory events $(30,31)$. For this reason, MMP expression patterns (MMP-1 MMP-28) associated with the remodeling of skin tissues were tested using a Bi-Plex expression methodology (31). The DNFB-induced 
$\mathbf{a}$

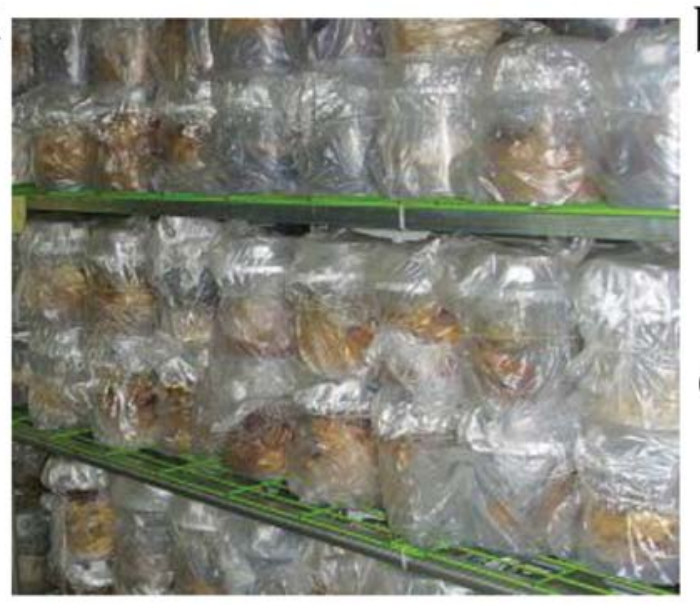

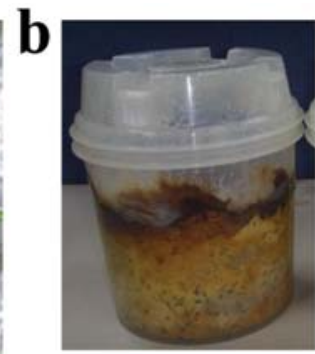

C

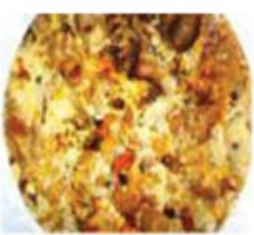

Figure 1. A classical feature of (a) solid fermentation of various plants and (b) a plastic bottle for solid fermentation with (c) mycelia growth of Phellinus baumii.

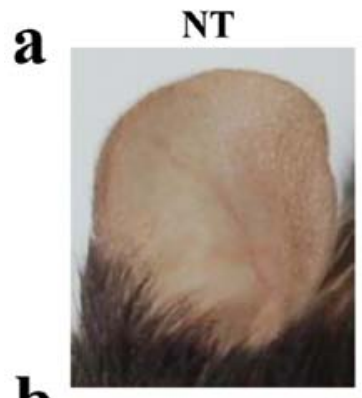

b

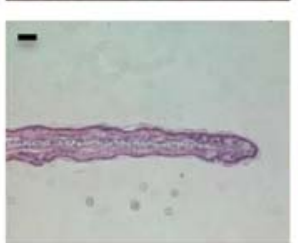

$\mathbf{c}$

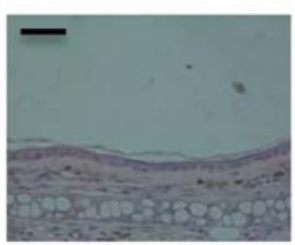

DNFB
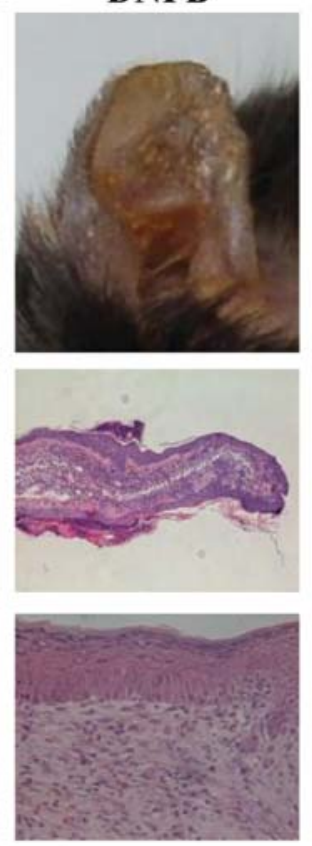

$\mathrm{Cc}$
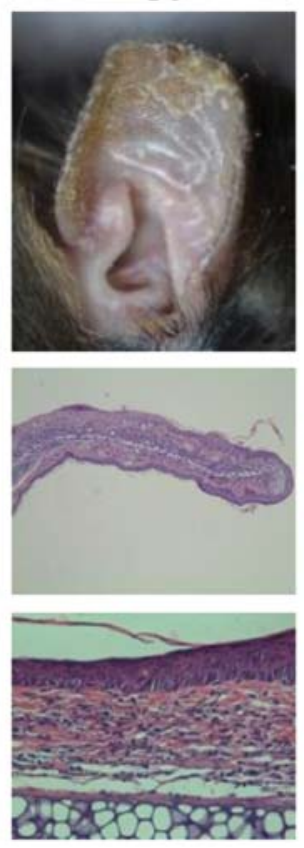

$\mathrm{Pb}$
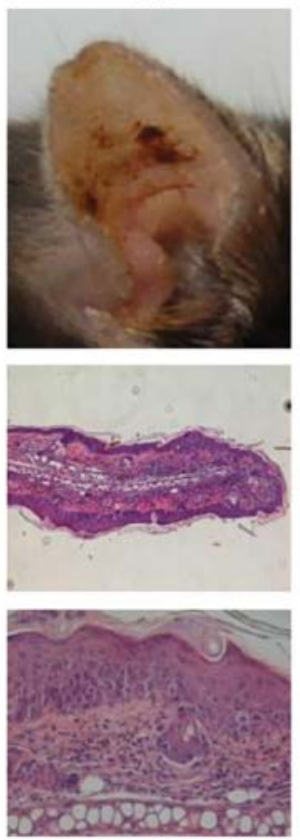

af $\mathrm{Cc} / \mathrm{Pb}$
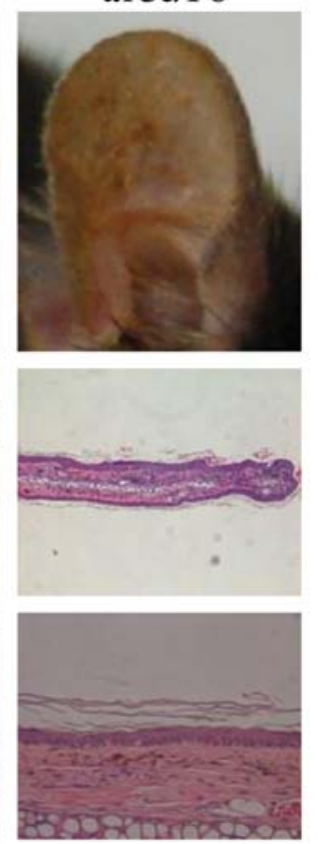

Figure 2. Inhibitory effects of Cinnamomum cassia fermentation with Phellinus baumii on the inflammation in 2,4-dinitrofluorobenzene (DNFB)-induced atopy models. Apart from the not treated (NT) group, all the sample groups were treated with $0.2 \%$ DNFB. (a) Appearance of the ear. Five mice were used in each group. (b and c) Histochemical analysis by hematoxylin and eosin staining. Scale bar $200 \mu \mathrm{m}$, magnication, (b) x40 and (c) x100. The data represent a classical set of 3 independent experiments. Cc, Cinnamomum cassia; $\mathrm{Pb}$, Phellinus baumii; afCc/Pb, aqueous fraction produced by solid fermentation of Phellinus baumii on Cinnamomum cassia.
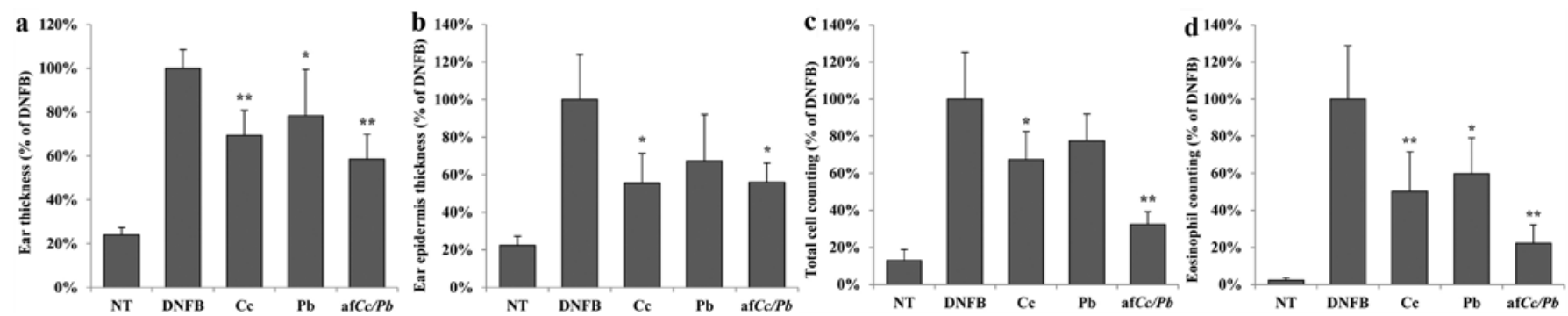

Figure 3. Effects of an aqueous extract of Cinnamomum cassia fermentation with Phellinus baumii (afCc/Pb) on 2,4-dinitrofluorobenzene (DNFB)-induced atopic inflammation in C57BL $/ 6$ mice. DNFB solution $(0.2 \%, \mathrm{w} / \mathrm{v})$ was applied to the mouse skin. Control (vehicle-only) mice were similarly treated with acetone (without DNFB). af $C c / P b$ was used at a concentration of $30 \mu \mathrm{g} / \mathrm{ml}$. (a and b) Alleviation of ear or epidermis swelling by application of af $C c / P b$. Thickness was measured using a vernier caliper and is shown as relative \% of the control. Data are expressed as mean \pm standard deviation $(\mathrm{n}=5)$; ${ }^{*} \mathrm{P}<0.05$. Decreases in (c) total cell number or (d) eosinophil number in DNFB-treated ear tissue upon application of af $C c / P b$. Cells were counted using phase contrast microscopy in 9 blocks of a hematocytometer and compared to the control values. Data are expressed as the means \pm standard deviation $(\mathrm{n}=5)$. ${ }^{*} \mathrm{P}<0.05,{ }^{* *} \mathrm{P}<0.01$. 


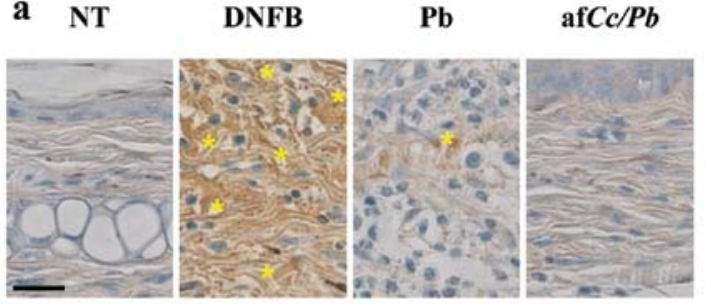

c

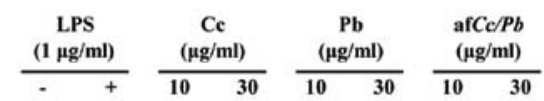

MMP-3

MMP-10

MMP-12

MMP-14

GAPDH

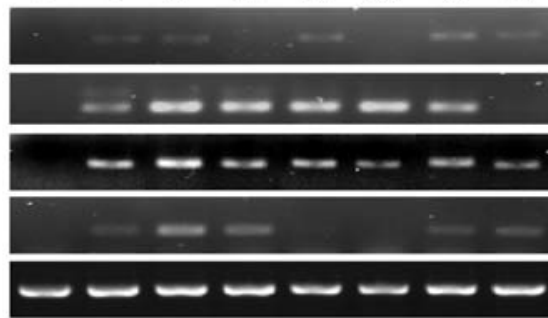

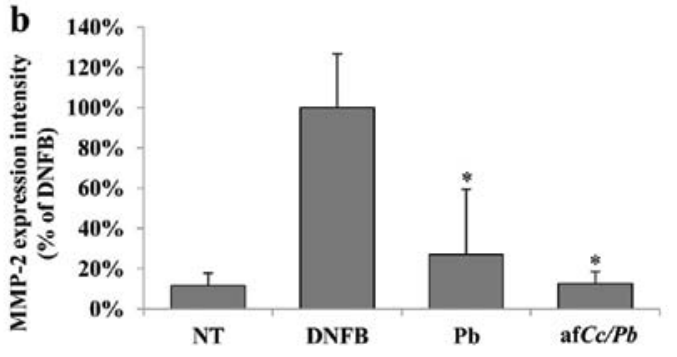

d

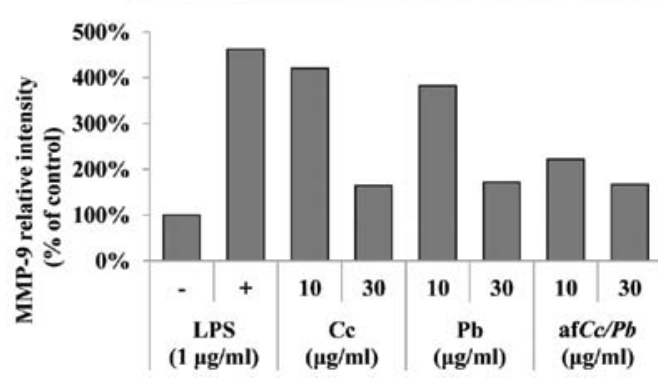

Figure 4. Inhibition of matrix metalloproteinase (MMP) expression with or without the application of aqueous extract of Cinnamomum cassia fermentation with Phellinus baumii (afCc/Pb). (a) The levels of MMP-2-positive cells in 2,4-dinitrofluorobenzene (DNFB)-treated mice were assayed. Asterisks indicate cells expressing these proteins. Scale bar, $25 \mu \mathrm{m}$. (b) Mouse spleen cells were photographed under a phase contrast microscope and show a relative intensity. Data are expressed as mean \pm standard deviation $(n=5) .{ }^{*} \mathrm{P}<0.05$. (c) Reverse transcription polymerase chain reaction (RT-PCR) analysis of MMP inhibition. The RT-PCR conditions are described in detail in the Materials and Method section. (d) Zymography analysis of MMP-9 expression in response to af $C c / P b$.
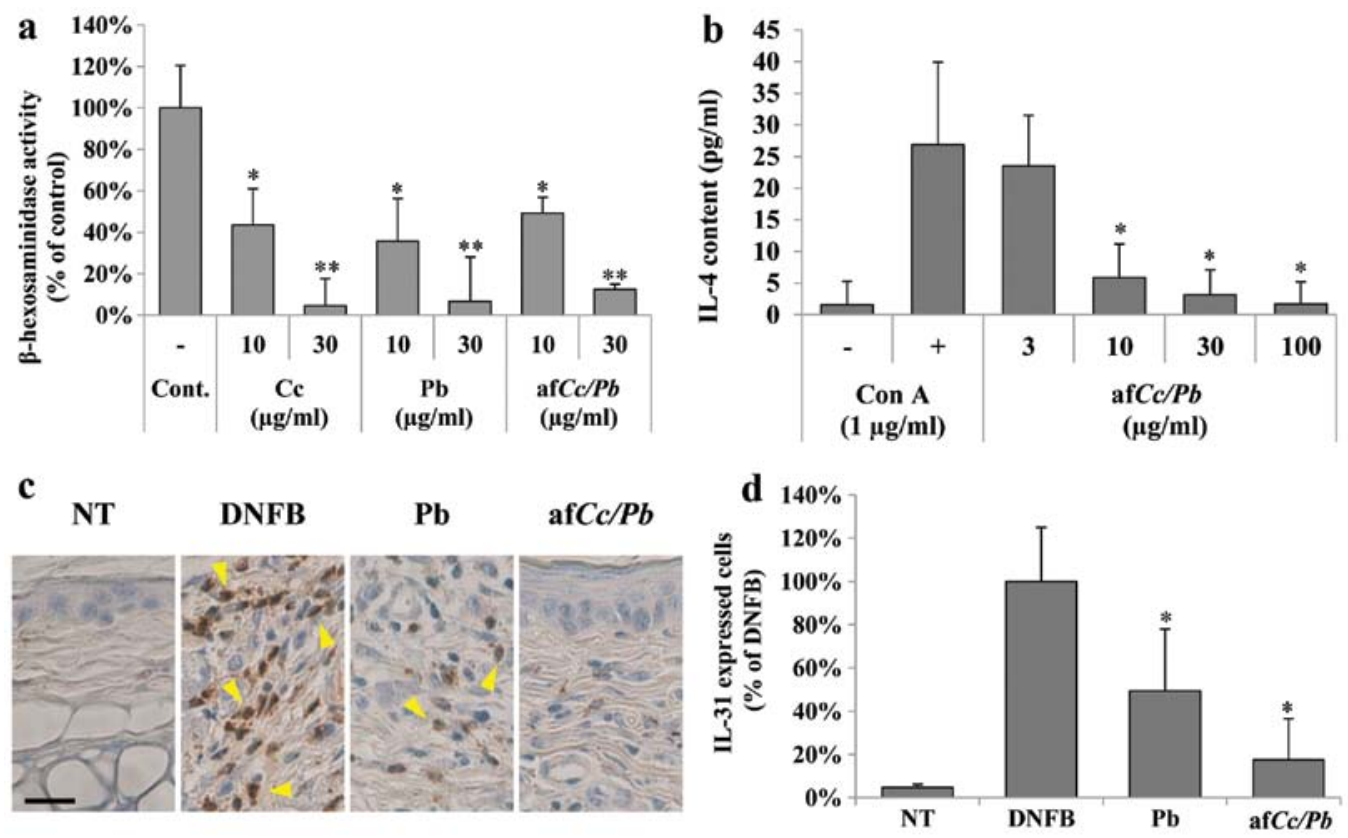

Figure 5. Inhibitory effect of aqueous extract of Cinnamomum cassia fermentation with Phellinus baumii (afCc/Pb) on cytokine expression. (a) $\beta$-hexosaminidase activity was measured as described in the Materials and methods section with a slight modification. (b) Interleukin-4 (IL-4) content was examined using a commercial enzyme-linked immunosorbent assay (ELISA) kit for determination of mouse anti-IL-4 monoclonal antibodies. (c) The levels of IL-31-positive cells in 2,4-dinitrofluorobenzene (DNFB)-treated mice were assayed. Asterisks indicate cells expressing these proteins. Scale bar, $25 \mu \mathrm{m}$. (d) Cells were photographed under a phase contrast microscope and counted as relative intensity. Data are expressed as the means \pm standard deviation $(\mathrm{n}=5)$. ${ }^{*} \mathrm{P}<0.05,{ }^{* *} \mathrm{P}<0.01$. $\mathrm{Cc}$, C. cassia; $\mathrm{Pb}$, P. baumii; afCc/ $\mathrm{Pb}$, aqueous fraction produced by solid fermentation of P. baumii on C. cassia.

expression of other biomarkers (intercellular adhesion molecule 1, vasopressin-activated calcium-mobilizing protein, $\beta$-catennin, cluster of differentiation 44, profillin and paxillin) was not altered by afCc/Pb treatment (32 and data not shown).

IL-4, -13, -25, -29, -31, -33 -and/or -35 are well-documented to be specifically expressed during severe skin inflammation/lesions (33). In particular, numerous studies have revealed the involvement of IL-4, $-13,-25$ and -31 , by investigating their expression in skin tissues derived from an animal model of allergic conditions (33-35). For this reason, $\beta$-hexosaminidase activity was measured first in RAW 264.7 cells. Compared to the control, afCc/Pb treatment 
reduced $\beta$-hexosaminidase activity in a dose-dependent fashion (Fig. 5a), indicating that degranulation is significantly decreased by such treatment. The IL-4 content was also clearly reduced by af $C c / P b$ treatment (Fig. 5 b, bars 3 to 6) in RAW 264.7 cells. These results raised the question of IL-31 expression, a potential anti-atopic biomarker in atopic-dermatitis animal models (36). As shown in Fig. 5c (arrowheads), immunohistochemistry results revealed that afC $\mathrm{C} / \mathrm{Pb}$ treatment $(30 \mu \mathrm{g} / \mathrm{ml})$ ameliorated DNFB-induced atopic dermatitis symptoms, and evidently decreased the number of IL-31 expressing cells by $<87.8 \%$ of the level of DNFB-treated cells (Fig. 5d). C. cassia bark contains a variety of biologically active components, including linalool, eugenol and cinamic aldehyde, although they may partially induce allergic symptoms. Decursin or coumarin compounds are conversely assumed to have potential in alleviating this type of atopic dermatitis. Therefore, solid fermentation on the surface of various herbs is an important technology to reduce toxic materials, such as allergens, as well as to increase the availability of beneficial anti-atopic agents.

In conclusion, afCc/Pb ameliorated atopic inflammation by reducing the symptoms of atopy. The present study on the solid-state fermentation-based functionality of $C$. cassia highlights a preventive medication, as well as the availability of whole food biomaterials effective against atopic dermatitis, in that microbial bioconversion by solid fermentation is advantageous by not only increasing the yield of useful components, but also decreasing associated toxic substances. Further studies should focus on the reduction of toxic ingredients, as well as the increase of food biomaterials with health benefits.

\section{Acknowledgements}

The present study was supported by the National Research Foundation of Korea (NRF) funded by the Ministry of Science, ICT and Future Planning (NRF-2014R1A2A2A01006882).

\section{References}

1. Akilen R, Tsiami A, Devendra D and Robinson N: Cinnamon in glycaemic control: Systematic review and meta analysis. Clin Nutr 31: 609-615, 2012.

2. Mau J, Chen C and Hsieh P: Antimicrobial effect of extracts from Chinese chive, cinnamon, and corni fructus. J Agric Food Chem 49: 183-188, 2001.

3. Sung YY, Yoon T, Jang JY, Park SJ, Jeong GH and Kim HK: Inhibitory effects of Cinnamomum cassia extract on atopic dermatitis-like skin lesions induced by mite antigen in $\mathrm{NC} / \mathrm{Nga}$ mice. J Ethnopharmacol 133: 621-628, 2011.

4. Yang CH, Li RX and Chuang LY: Antioxidant activity of various parts of Cinnamomum cassia extracted with different extraction methods. Molecules 17: 7294-7304, 2012.

5. Kobayashi Y: Langerhans' cells produce Type IV collagenase (MMP-9) following epicutaneous stimulation with haptens. Immunology 90: 496-501, 1997.

6. Nam DY, Lee JM, Heo JC and Lee SH: Mitigation of 2,4-dinitrofluorobenzene-induced atopic dermatitis-related symptoms by Terminalia chebula Retzius. Int J Mol Med 28: 1013-1018, 2011.

7. Jin H, Kumar L, Mathias C, Zurakowski D, Oettgen H, Gorelik L and Geha R: Toll-like receptor 2 is important for the $\mathrm{T}(\mathrm{H}) 1$ response to cutaneous sensitization. J Allergy Clin Immunol 123: 875-882, 2009

8. Martins S, Mussatto SI, Martínez-Avila G, Montañez-Saenz J, Aguilar CN and Teixeira JA: Bioactive phenolic compounds: production and extraction by solid-state fermentation. Biotechnol Adv 29: 365-373, 2011.
9. Rahardjo YSP, Tramper J and Rinzema A: Modeling conversion and transport phenomena in solid-state fermentation: A review and perspectives. Biotechnol Adv 24: 161-179, 2006.

10. Martins S, Teixeira JA and Mussatto SI: Solid-state fermentation as a strategy to improve the bioactive compounds recovery from Larrea tridentata leaves. Appl Biochem Biotechnol 171: 1227-1239, 2013

11. Charlton E: Committee on ethical issues of the international association for the study of pain, Pain 63: 277-278, 1995.

12. Cho EJ, Hwang HJ, Kim SW, Oh JY, Baek YM, Choi JW, Bae SH and Yun JW: Hypoglycemic effects of exopolysaccharides produced by mycelial cultures of two different mushrooms Tremella fuciformis and Phellinus baumii in ob/ob mice. Appl Microbiol Biotechnol 75: 1257-1265, 2007.

13. Hölker U, Höfer M and Lenz J: Biotechnological advantages of laboratory-scale solid-state fermentation with fungi. Appl Microbiol Biotechnol 64: 175-186, 2004.

14. Sato Y, Mukai K, Watanabe S, Goto M and Shimosato Y: The AMeX method. A simplified technique of tissue processing and paraffin embedding with improved preservation of antigens for immunostaining. Am J Pathol 125: 431-435, 1986.

15. Heo JC, Woo SU, Kweon MA, Park JY, Lee HK, Son M, Rho JR and Lee SH: Aqueous extract of the Helianthus annuus seed alleviates asthmatic symptoms in vivo. Int J Mol Med 21: 57-61, 2008.

16. Djukanović R, Lai CK, Wilson JW, Britten KM, Wilson SJ, Roche WR, Howarth PH and Holgate ST: Bronchial mucosal manifestations of atopy: a comparison of markers of inflammation between atopic asthmatics, atopic nonasthmatics and healthy controls. Eur Respir J 5: 583-544, 1992.

17. Yoo JM, Sok DE and Kim MR: Effect of endocannabinoids on IgE-mediated allergic response in RBL-2H3 cells. Int Immunopharmacol 17: 123-131, 2013.

18. Heo JC, Nam SH, Nam DY, Kim JG, Lee KG, Yeo JH, Yoon CS, Park CH and Lee SH: Anti-asthmatic activities in mycelial extract and culture filtrate of Cordyceps sphecocephala J201. Int J Mol Med 26: 351-356, 2010.

19. Shimizu T, Kanai K, Kyo Y, Asano K, Hisamitsu T and Suzaki H: Effect of tranilast on matrix metalloproteinase production from neutrophils in-vitro. J Pharm Pharmacol 58: 91-99, 2006.

20. Munaut C, Noël A, Hougrand O, Foidart JM, Boniver J and Deprez M: Vascular endothelial growth factor expression correlates with matrix metalloproteinases MT1-MMP, MMP-2 and MMP-9 in human glioblastomas. Int J Cancer 106: 848-855, 2003.

21. Wei ZF, Tong B, Xia YF, Lu Q, Chou GX, Wang ZT and Dai Y: Norisoboldine suppresses osteoclast differentiation through preventing the accumulation of TRAF6-TAK1 complexes and activation of MAPKs/NF- $\mathrm{BB} / \mathrm{c}-\mathrm{Fos} / \mathrm{NFATc} 1$ pathways. PLoS One 8: e59171, 2013.

22. Hendrickson LM, Zhao-Shea R and Tapper AR: Modulation of ethanol drinking-in-the-dark by mecamylamine and nicotinic acetylcholine receptor agonists in C57BL/6 J mice. Psychopharmacology (Berl) 204: 563-572, 2009.

23. Ponikau JU, Sherris DA, Kephart GM, Kern EB, Gaffey TA, Tarara JE and Kita H: Features of airway remodeling and eosinophilic inflammation in chronic rhinosinusitis: is the histopathology similar to asthma? J Allergy Clin Immunol 112: 877-882, 2003.

24. Lee JD: Definition of food material and identification. Ministry of Food and Drug Safety in Korea. Available at http://rnd.mfds.go.kr, 2004.

25. Wasser SP and Weis AL: Therapeutic effects of substances occurring in higher Basidiomycetes mushrooms: a modern perspective. Crit Rev Immunol 19: 65-96, 1999.

26. Kim SP, Kang MY, Kim JH, Nam SH and Friedman M: Composition and mechanism of antitumor effects of Hericium erinaceus mushroom extracts in tumor-bearing mice. J Agric Food Chem 59: 9861-9899, 2011.

27. Pandey A: Solid-state fermentation. Biochem Eng J 13: 81-84, 2003.

28. Lü ZR, Park D, Lee KA, Ryu JW, Bhak J, Shi L, Lee DY, Park YD, Zou F and Yang JM: Profiling the dysregulated genes of keratinocytes in atopic dermatitis patients: cDNA microarray and interactomic analyses. J Dermatol Sci 54: 126-129, 2009.

29. Harper JI1, Godwin H, Green A, Wilkes LE, Holden NJ, Moffatt M, Cookson WO, Layton G and Chandler S: A study of matrix metalloproteinase expression and activity in atopic dermatitis using a novel skin wash sampling assay for functional biomarker analysis. Br J Dermatol 162: 397-403, 2010. 
30. Khorramizadeh MR, Falak R, Pezeshki M, Safavifar F, Mansouri P, Ghahary A, Saadat F and Varshokar K: Dermal wound fibroblasts and matrix metaloproteinases (MMPs): their possible role in allergic contact dermatitis. Iran J Allergy Asthma Immunol 3: 7-11, 2004.

31. Suzukawa M, Komiya A, Iikura M, Nagase H, YoshimuraUchiyama C, Yamada H, Kawasaki H, Ohta K, Matsushima K, Hirai K, Yamamoto K and Yamaguchi M: Trans-basement membrane migration of human basophils: role of matrix metalloproteinase-9. Int Immunol 18: 1575-1583, 2006.

32. Mu H, Ohashi R, Yan S, Chai H, Yang H, Lin P, Yao Q and Chen C: Adipokine resistin promotes in vitro angiogenesis of human endothelial cells. Cardiovasc Res 70: 146-57, 2006.

33. Heo JC, Nam DY, Seo MS and Lee SH: Alleviation of atopic-dermatitis-related symptoms by Perilla frutescens Button. Int J Mol Med 28: 733-738, 2011.
34. Lee J, Noh G, Lee S, Youn Y and Rhim J: Atopic dermatitis and cytokines: recent patents in immunoregulatory and therapeutic implications of cytokines in atopic dermatitis. part I: cytokines in atopic dermatitis. Recent Pat Inflamm Allergy Drug Discov 6: 222-247, 2012.

35. Imai Y, Yasuda K, Sakaguchi Y, Haneda T, Mizutani H, Yoshimoto T, Nakanishi K and Yamanishi K: Skin-specific expression of IL-33 activates group 2 innate lymphoid cells and elicits atopic dermatitis-like inflammation in mice. Proc Natl Acad Sci 110: 13921-13926, 2013.

36. Bilsborough J, Leung DY, Maurer M, Howell M, Boguniewicz M, Yao L, Storey H, LeCiel C, Harder B and Gross JA: IL-31 is associated with cutaneous lymphocyte antigen-positive skin homing T cells in patients with atopic dermatitis. J Allergy Clin Immunol 117: 418-425, 2006 